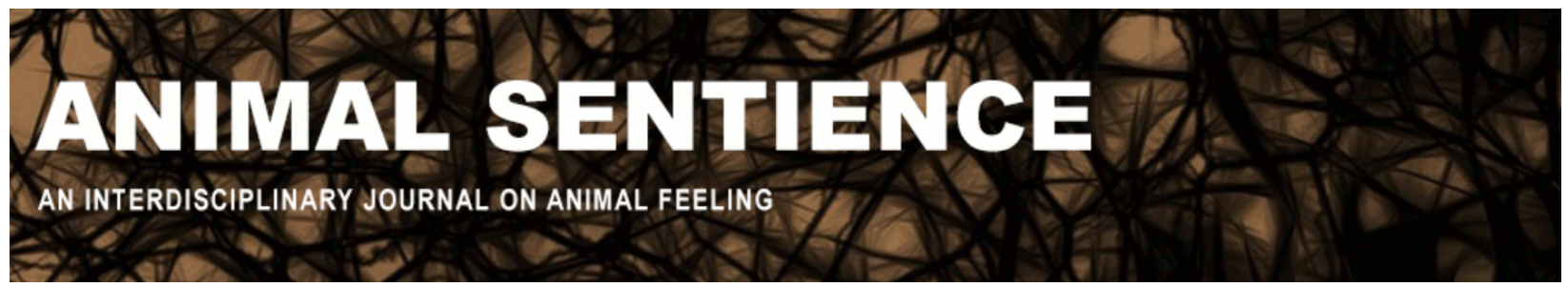

Rose, James D. (2016) Pain in fish: Weighing the evidence. Animal Sentience $3(25)$

DOI: $10.51291 / 2377-7478.1049$

Date of submission: $2015-10-25$

Date of acceptance: 2015-12-13

(c)

This article has appeared in the journal Animal

Sentience, a peer-reviewed journal on animal

cognition and feeling. It has been made open access,

free for all, by WellBeing International and deposited

in the WBI Studies Repository. For more information,

please contact

wbisr-info@wellbeingintl.org.

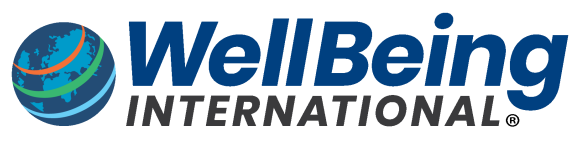

SOLUTIONS FOR PEOPLE, ANIMALS AND ENVIRONMENT 


\title{
Pain in fish: Weighing the evidence
}

Commentary on Key on Fish Pain

\author{
James D. Rose \\ Department of Zoology and Physiology \\ University of Wyoming
}

\begin{abstract}
The target article by Key (2016) examines whether fish have brain structures capable of mediating pain perception and consciousness, functions known to depend on the neocortex in humans. He concludes, as others have concluded (Rose 2002, 2007; Rose et al. 2014), that such functions are impossible for fish brains. This conclusion has been met with hypothetical assertions by others to the effect that functions of pain and consciousness may well be possible through unknown alternate neural processes. Key's argument would be bolstered by consideration of other neurological as well as behavioral evidence, which shows that sharks and ray are fishes that have no nociceptive afferents and that bony fishes, although they have A delta nociceptors, are extremely deficient in C fibers, the most abundant nociceptor in mammals. In addition, behavioral studies of surgery, angling and other putatively noxious procedures show that fish don't behave as if they suffer from pain.
\end{abstract}

James D. Rose trout@uwyo.edu Professor Emeritus, Department of Zoology, University of Wyoming, had a 37-year career of research in neurophysiology, neuroanatomy and neuroendocrinology relating to behavior in many species of mammals, including humans, as well as fishes, amphibians and reptiles.

http://www.uwyo.edu/registrar/university catalog/2aszoo.html

The possibility of pain experience in fish has been a subject of importance to me for many years, so it is useful to compare the present target article by Key (2016) with those I have published on the same subject. The main question of Key's paper, like mine, is: Given what we know about the neurological basis of pain in humans - the only species where we have unequivocal evidence of pain experience - is the nervous system of fish likely to be able to generate this or a similar experience? Key's paper and mine utilized similar kinds of evidence regarding the neural, particularly cortical, bases of pain and of consciousness in humans. Likewise, we both contrasted that evidence with the evidence that fish forebrains lack the kinds of structural and functional organization likely to be essential to either pain or consciousness. We differ, sometimes significantly, in our treatment of this material, but arrive at the same conclusion for largely the same reasons.

My most important concern about this target article is that in limiting its scope to the brain argument, it doesn't make as strong a case against the possibility of fish pain as it could. There is a large amount of behavioral evidence contradicting the idea that fish feel pain. Key mentions the lack of effect of craniotomy on fish behavior, but there is a wide range of other surgical interventions, like transmitter implants, that show a remarkable lack of effect on fish behavior. There is also a large body of data from angling studies as well as recent experimental studies of oral acid injections or hooking, which fail to show a level of reactivity consistent with well- 
developed pain perception (Rose et al. 2014).

The question then becomes, if fish can feel pain, why don't they act like it? This behavioral evidence also indicates that not only is conscious pain not likely, but nociception, the unconscious processing of injury signals, is not well developed. Why fish don't react to injurious stimuli is understandable, not only because they don't have the requisite cortical structures for it, but because they also have very limited nociceptive afferents. Although bony fishes have $A$ delta receptors, which in humans (with cortical processing) trigger rapid, brief, localized, stinging "first pain," bony fishes have very few unmyelinated $\mathrm{C}$ nociceptors. C nociceptors are the most abundant somatic sensory nerve fiber in humans and other mammals and, with cortical processing, trigger "second pain" - the slowly-developing, poorly localized, sustained, highly noxious, burning, aching pain experience. Furthermore, cartilaginous fishes, the sharks and rays, have no nociceptors for detecting injury at all, categorically ruling out a capacity for pain.

Do bony fishes have brain specializations for conscious pain when sharks couldn't use such a thing? This is particularly important because sharks and rays, like bony fishes, swim away and some even jump when hooked by an angler, bringing into question the interpretation that fishes swim away when hooked because they are in pain (Rose 2007). The commitment, by some, to the belief that fish must be able to feel pain and to suffer should also be considered in light of the way fish actually live and survive, where such a capacity would more likely be detrimental than beneficial (Rose 2007, Rose et al. 2014). Clearly, sharks and rays are fishes that have survived perfectly well without the burden of pain. Bony fishes might use their limited capacity for nociception to avoid injurious stimuli rapidly, but their behavior belies the notion that pain and suffering should be considered a biological imperative for them.

Key's target article examines the neural basis of consciousness and, like my previous papers, argues that there is extensive, compelling evidence that consciousness, like pain, depends on processes in the neocortex. In fact, the cortical regions critical for consciousness are essentially the same as those mediating pain, whereas sensory and motor cortical regions are incapable, by themselves, of generating consciousness (Rose 2002, 2007). Key goes on to argue that fishes are neurologically incapable of consciousness, an essential condition for pain experience. Counterarguments have been made that pain and consciousness might be generated in the fish brain through unknown, alternative mechanisms. So far, such arguments remain speculative since no plausible alternative mechanisms have been proposed, much less demonstrated. Numerous examples of fish behavior have been claimed to be evidence of consciousness (e.g., Braithwaite 2010), but a critical examination of these claims shows them to be unconvincing for reasons explained by Rose et al. (2014).

Key gives an extensive consideration to the diversity of behaviors that should not be taken as evidence of pain, particularly those that can be expressed by actions of the brainstem and spinal cord. I don't think, however, that it is valid to delimit the categorization of unconscious behaviors as "reflexive," because there are a great many highly complex, non-reflexive behaviors in humans that are unconscious (Rose 2002, 2007, Rose et al. 2014). Also troublesome is Key's criterion for behavioral evidence of pain: that a behavior can be disrupted. This has been a consistent error in behavioral studies purporting to show pain in fish as explained in detail in 
previous papers (Rose 2007, Rose et al. 2014). In fact, the vast majority of behaviors that have been commonly used to assess pain in mammals do not adequately distinguish nocifensive reactions from genuinely pain-mediated, conscious reactions (Rose and Woodbury 2008).

Regarding the contentious issue of consciousness, I am inclined to agree with a position recently expressed by Dawkins (2012), that the question of animal consciousness is unlikely to be decisively resolved for some time, but that welfare considerations for animals don't hinge on assuming them to be conscious.

\section{References}

Braithwaite, V. (2010). Do Fish Feel Pain? New York, NY: Oxford University Press.

Dawkins, M.S. (2012). Why Animals Matter. Oxford: Oxford University Press.

Key, B. (2016). Why fish do not feel pain. Animal Sentience 2016.003.

Rose, J.D. (2002). The neurobehavioral nature of fishes and the question of pain. Reviews in Fisheries Science, 10: 1-38.

Rose, J.D. (2007). Anthropomorphism and 'mental welfare' of fishes. Diseases of Aquatic Organisms, 75: 139-154.

Rose, J. D. and Woodbury, C.J. (2008). Animal models of nociception and pain. In: Sourcebook of Models for Biomedical Research. (Ed. P.M. Conn). Totowa, NJ: Humana Press.

Rose, J.D., Arlinghaus, R., Cooke, S.J., Diggles, B.K., Sawynok, W., Stevens, E.D. and Wynne, C.D.L. (2014). Can fish really feel pain? Fish and Fisheries, 15: 97-133. 